08

\title{
Механизм образования клатратов аргона с углеродными дендритами
}

\author{
(C) М.П. Данилаев, ${ }^{1}$ E.М. Зуева, ${ }^{2,3}$ E.А. Богослов, ${ }^{1}$ М.С. Пудовкин, ${ }^{3}$ Ю.Е. Польский ${ }^{1}$ \\ ${ }^{1}$ Казанский национальный исследовательский технический университет им. А.Н. Туполева - КАИ, \\ 420111 Казань, Россия \\ ${ }^{2}$ Институт органической и фризической химии им. А.Е. Арбузова КазНЦ РАН, \\ 420088 Казань, Россия \\ ${ }^{3}$ Казанский (Приволжский) фредеральный университет, \\ 420008 Казань, Россия \\ e-mail: danilaev@mail.ru
}

(Поступило в Редакцию 24 июля 20017 г.)

\begin{abstract}
Изучен механизм образования клатратов аргона с углеродными дендритами, полученными в плазме газового разряда атмосферного давления. Показано, что образование таких клатратов происходит за счет разницы в характерных временах — времени „жизни“ молекул, содержащих атомы аргона, и времени образования связей С-С. Отмечено, что образование клатратов аргона с углеродными дендритами возможно только при одновременном выполнении нескольких условий: условия образования молекул-,ловушек“ в разряде; относительно низкой температуре в центральной части дугового разряда, а также наличии активных частиц углерода, образуемых за счет разложения в плазме исходных углеводородов. Выполнение всех этих условий определяется в основном составом смеси исходных углеводородов и плотностью тока разряда, что подтверждено экспериментальными исследованиями.
\end{abstract}

DOI: 10.21883/JTF.2018.06.46020.2456

Известно, что атомы инертных газов (Ar, $\mathrm{Kr}, \mathrm{Xe})$ могут удерживаться внутри кристаллической решетки вещества, молекулы которого образуют водородные связи. Такие соединения включения получили название клатратов $[1,2]$. В последнее время появляются работы $[3,4]$, в которых атомы инертных газов обнаружены в субмикронных частицах твердых тел с аморфной структурой. C точки зрения практического применения такие образования представляют интерес для медицины. Например, клатраты радиоактивных изотопов инертных газов с углеродными или кремниевыми субмикронными частицами можно использовать в радионуклидной терапии онкологических заболеваний $[5,6]$. Эта сфера практического применения требует точного дозирования излучения, а следовательно, контроля количества атомов изотопов инертных газов в субмикронных частицах. Контроль количества атомов изотопов инертных газов при получении их клатратов с субмикронными частицами требует четкого представления о механизме их образования, который не всегда является очевидным. Так, при обнаружении клатратов аргона с углеродными дендритами, полученных в плазме дугового разряда, была высказана гипотеза [3] об эксимерном механизме их формирования. Целью настоящей работы является уточнение механизма образования клатратов инертных газов с углеродными дендритами.

Типовая структура углеродного дендрита, полученного в плазме дугового разряда [3], представлена на рис. 1.

В общем случае в поперечном сечении углеродного дендрита, полученного в дуговом разряде, можно выделить три области (рис. 1): 1 - ядро, 2 - промежуточный слой, 3 - внешняя оболочка. Структура дендрита в каждой области различна и определяется условиями его получения: исходными углеводородами, из которых образуется дендрит, мощностью и плотностью тока разряда, а также давлением в разрядной камере и газовым составом [3,7]. Так, при характерном значении кинетической температуры в центральной части разряда $\sim 1000^{\circ} \mathrm{C}$ ядро представляет собой неупорядоченные слои графеновых „чешуек“ (graphene „sheets“). С ростом плотности тока и, как следствие, температуры графеновые „чешуйки“ начинают упорядочиваться, ориентируясь радиально по градиенту температуры [8]. Поскольку графен непроницаем для атомов любых газов [9], атомы аргона могут оказаться „запертыми“ в ядре дендрита

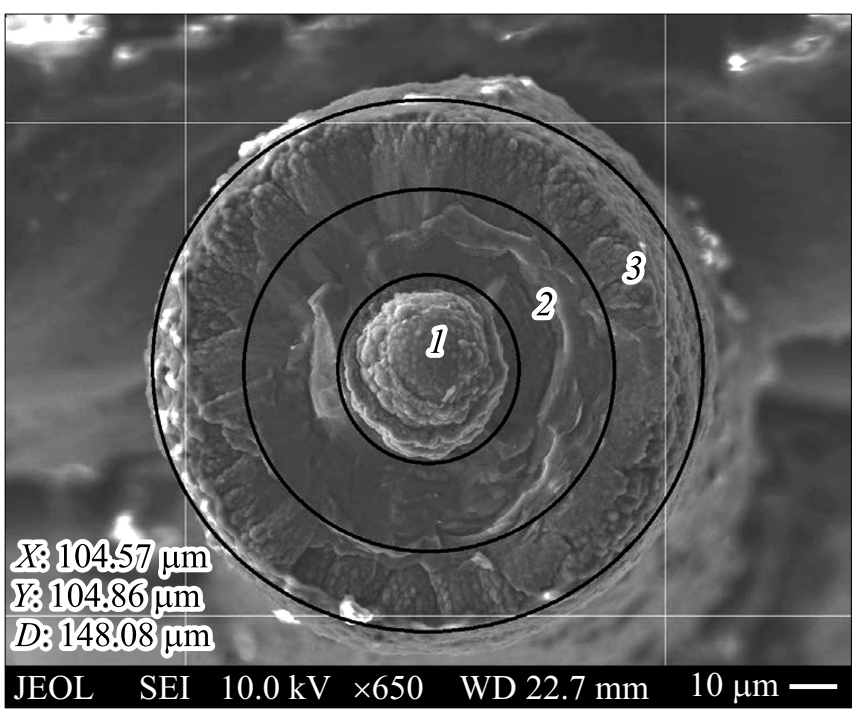

Рис. 1. Типовая структура углеродного дендрита в поперечном сечении. 
только в том случае, если графеновые „чешуйки“ не упорядочены. При упорядочивании графеновых „чешуек“ атомы аргона выходят из дендрита между слоями графена.

Предполагаемый механизм „пленения“ атомов аргона в ядре дендрита основан на образовании в плазме дугового разряда молекул со связью $\mathrm{Ar}-\mathrm{C}$ (молекул-,,ловушек“), характерное время „жизни“ которых больше характерного времени образования связей $\mathrm{C}-\mathrm{C}$ [3]. Таким образом, пока атом аргона находится в молекуле, вокруг него успевают сформироваться графеновые „чешуйки“. За счет отсутствия упорядоченности графеновых „чешуек“ атом аргона после распада молекулы остается „запертым“ в образовавшейся полости. Однако для осуществления такого механизма необходимо одновременное выполнение нескольких условий: условие образования молекул со связью $\mathrm{Ar}-\mathrm{C}$ в разряде, относительно низкая температура в центральной части дугового разряда, а также наличие активных частиц углерода, образуемых за счет разложения в плазме исходных углеводородов. Выполнение всех этих условий определяется в основном составом смеси исходных углеводородов и плотностью тока разряда [3,10,11].

Для уточнения предполагаемого механизма были проведены квантово-химические расчеты методами MP2 и TD-CAM-B3LYP с использованием базисного набора aug-cc-pVDZ с помощью программного пакета ORCA 4.0 [12]. В качестве исходных углеводородов для синтеза дендритов использовались газообразные продукты деструкции полимеров (полиэтилена, полипропилена и полистирола), которые подавались в разрядную камеру с помощью газа-носителя аргона [13]. Поскольку влияние состава смеси исходных углеводородов, попадающей в разрядную камеру, может быть определяющим при образовании клатратов аргона, была проведена оценка энергий гомолитического разрыва химических связей в полиэтилене (PE), полипропилене (PР) и полистироле (PS). В качестве модели полимерной цепи использовалась молекула $\mathrm{CH}_{3}-\mathrm{CHR}-\mathrm{CH}_{2}-\mathrm{CH}_{3}$, содержащая элементарное звено $-\mathrm{CHR}-\mathrm{CH}_{2}-$ перечисленных выше полимеров $\left(\mathrm{R}=\mathrm{H}\right.$ для $\mathrm{PE}, \mathrm{R}=\mathrm{CH}_{3}$ для $\mathrm{PP}, \mathrm{R}=\mathrm{C}_{6} \mathrm{H}_{5}$ для $\mathrm{PS})$. Согласно MP2 расчетам, энергии связей $\mathrm{C}-\mathrm{C}$ и $\mathrm{C}-\mathrm{R}$ равны 4.2 и $4.4 \mathrm{eV}$ (в PE), 4.2 и $4.2 \mathrm{eV}$ (в PP), 4.9 и $6.0 \mathrm{eV}$ (в PS). Таким образом, в случае PР процесс гомолитического разрыва химических связей протекает с меньшей затратой энергии. Отметим также, что образующиеся свободные радикалы и продукты их рекомбинации способны к образованию ассоциатов с атомом аргона за счет вандерваальсового взаимодействия с положительно поляризованными атомами водорода, однако, согласно MP2 расчетам, это взаимодействие слабое (его энергия меньше $0.1 \mathrm{eV}$, кратчайшие расстояния $\mathrm{Ar} \ldots \mathrm{H}$ больше $3 \AA$ ), поэтому такие ассоциаты неустойчивы.

Проведенные квантово-химические расчеты показывают, что в случае РР смесь исходных углеводородов, попадающая в разрядную камеру, содержит большое количество низкомолекулярных алифатических углеводородов и их радикалов, что обеспечивает высокую плотность тока разряда. В условиях высокой плотности тока разряда происходит глубокий крекинг с образованием ацетиленовых углеводородов и их радикалов.

Компьютерный поиск молекул со связью $\mathrm{Ar}-\mathrm{C}$ осуществлялся как на основных (MP2), так и на возбужденных (TD-CAM-B3LYP) поверхностях потенциальной энергии - синглетных $(S=0)$, дублетных $(S=1 / 2)$ и триплетных $(S=1)$. Был обнаружен единственный минимум (на основной синглетной поверхности), соответствующий молекуле $\mathrm{HC} \equiv \mathrm{C}-\mathrm{Ar}-\mathrm{C} \equiv \mathrm{CH}$ (длина связей $\mathrm{Ar}-\mathrm{C}$ равна $2.14 \AA$ ). Отметим, что в работе [14] было предсказано существование молекулы $\mathrm{F}-\mathrm{Ar}-\mathrm{C} \equiv \mathrm{CH}$ с более короткой связью $\mathrm{Ar}-\mathrm{C}$ (длина связи $1.86 \AA$ ). Было показано, что связь $\mathrm{Ar}-\mathrm{C}$ в этой молекуле, помимо ионной составляющей, характеризуется небольшим ковалентным вкладом.

Согласно MP2 расчетам, распад молекулы $\mathrm{HC} \equiv \mathrm{C}-\mathrm{Ar}-\mathrm{C} \equiv \mathrm{CH}$ на два радикала $\mathrm{HC} \equiv \mathrm{C}^{\bullet}$ и атом аргона, $\mathrm{HC} \equiv \mathrm{C}-\mathrm{Ar}-\mathrm{C} \equiv \mathrm{CH} \rightarrow 2 \mathrm{HC} \equiv \mathrm{C}^{\bullet}+\mathrm{Ar}$, происходит с поглощением энергии $(\Delta E=1.1 \mathrm{eV}$, т. е. энергия связи $\mathrm{Ar}-\mathrm{C}$ в молекуле $\mathrm{HC} \equiv \mathrm{C}-\mathrm{Ar}-\mathrm{C} \equiv \mathrm{CH}$ равна $0.5 \mathrm{eV}$ ). Это превращение характеризуется высоким потенциальным барьером [14]. Более вероятным механизмом разложения молекулы $\mathrm{HC} \equiv \mathrm{C}-\mathrm{Ar}-\mathrm{C} \equiv \mathrm{CH}$ является ее распад на молекулу $\mathrm{HC} \equiv \mathrm{C}-\mathrm{C} \equiv \mathrm{CH}$ и атом аргона: $\mathrm{HC} \equiv \mathrm{C}-\mathrm{Ar}-\mathrm{C} \equiv \mathrm{CH} \rightarrow \mathrm{HC} \equiv \mathrm{C}-\mathrm{C} \equiv \mathrm{CH}+\mathrm{Ar}$. Согласно MP2 расчетам, этот процесс протекает с выделением энергии $(\Delta E=-7.3 \mathrm{eV})$, т.е. молекула $\mathrm{HC} \equiv \mathrm{C}-\mathrm{Ar}-\mathrm{C} \equiv \mathrm{CH}$ является метастабильной. Кроме того, он характеризуется низким потенциальным барьером [14], т.е. молекула $\mathrm{HC} \equiv \mathrm{C}-\mathrm{Ar}-\mathrm{C} \equiv \mathrm{CH}$ кинетически малоустойчива к такому распаду. Тем не менее характерное время ее ,жизни“ может быть больше характерного времени образования связей $\mathrm{C}-\mathrm{C}$.

Поскольку в условиях высокой плотности тока разряда возможна ионизация атома аргона или углеводородного радикала, был осуществлен компьютерный поиск катионных молекул со связью $\mathrm{Ar}-\mathrm{C}$. Был обнаружен единственный минимум (на основной синглетной поверхности), соответствующий молекуле $\mathrm{HC} \equiv \mathrm{C}^{+} \leftarrow \mathrm{Ar}$ с очень короткой связью $\mathrm{Ar}-\mathrm{C}$ (длина связи всего $1.67 \AA$ ). Связь $\mathrm{Ar}-\mathrm{C}$ в этой молекуле образована по донорно-акцепторному механизму (энергия связи равна $3.2 \mathrm{eV})$. Молекула $\mathrm{HC} \equiv \mathrm{C}^{+} \leftarrow \mathrm{Ar}$ также является молекулой-,ловушкой“, характерное время „жизни“ которой больше характерного времени образования связей $\mathrm{C}-\mathrm{C}$.

Таким образом, проведенные квантово-химические расчеты показывают, что „пленение“ атомов аргона в углеродных дендритах возможно за счет образования молекул $\mathrm{HC} \equiv \mathrm{C}-\mathrm{Ar}-\mathrm{C} \equiv \mathrm{CH}$ и $\mathrm{HC} \equiv \mathrm{C}^{+} \leftarrow \mathrm{Ar}$, способных удерживать атом аргона дольше характерного времени формирования графеновых „чешуек“. Образование этих молекул возможно в условиях высокой плотности тока разряда, поэтому атомы аргона могут содержаться в основном в образцах, полученных из продуктов деструкции полипропилена. 
Для подтверждения сделанных заключений была проведена серия экспериментальных исследований. Схема экспериментальной установки приведена в работе [10]. Система стальных электродов разрядной камеры имела конфигурацию „игла-игла“. Разряд зажигался через диэлектрический барьер - керамику толщиной $1.5 \mathrm{~mm}$. Плазма барьерного разряда формировалась источником переменного напряжения с частотой $25 \mathrm{kHz}$. Напряженность электрического поля изменялась в пределах $\sim 1-10 \mathrm{kV} / \mathrm{cm}$ с погрешностью $\sim 10 \%$. В экспериментах обеспечивалось условие $T_{e} / T \sim 10$, где $T_{e}-$ температура электронов в плазме барьерного разряда, $T$ - кинетическая температура вблизи игольчатого электрода. Рост углеродных дендритов происходил с поверхности игл во встречном направлении до замыкания разрядного промежутка.

Первая серия экспериментов была направлена на уточнение механизма „пленения“ атомов аргона в углеродных дендритах. В качестве исходных углеводородов для синтеза дендритов использовались углеводороды двух типов: продукты деструкции полимеров, содержащих бензольное кольцо (PS), и продукты деструкции полимеров, не содержащих бензольного кольца (РЕ и РP). Наличие молекул со связью $\mathrm{Ar}-\mathrm{C}$ в газовом разряде исследовалось методом оптической просвечивающей спектроскопии с использованием спектрометpa StellarNet EPP2000 с разрешением $0.5 \mathrm{~nm}$. Типовые спектры приведены на рис. 2 при напряженности электрического поля $\sim 10 \mathrm{kV} / \mathrm{cm}$ и плотностях тока разряда $j_{\mathrm{PS}} \approx(25 \pm 3) \mathrm{mA} / \mathrm{cm}^{2}$ (при получении дендритов из продуктов деструкции $\mathrm{PS}$ ), $j_{\mathrm{PE}} / j_{\mathrm{PS}} \approx 2$ (при получении дендритов из продуктов деструкции РЕ) и $j_{\mathrm{PP}} / j_{\mathrm{PS}} \approx 3$ (при получении дендритов из продуктов деструкции РР). Оптические спектры (рис. 2) нормированы на спектр источника - водородной лампы ДВС-25.

Расчетные спектры поглощения (TD-CAM-B3LYP) предполагаемых молекул-,ловушек“ и продуктов их распада содержат полосы на следующих длинах волн (в $\mathrm{nm})$ :

434 (2), $412(2, f=0.01), 201(1, f=2.96), 199$ (2), $191(4)(\mathrm{HC} \equiv \mathrm{C}-\mathrm{Ar}-\mathrm{C} \equiv \mathrm{CH})$;

237 (1), 230 (1, $f=0.01), 225$ (2), 194 (1), 184 (1) $\left(\mathrm{HC} \equiv \mathrm{C}^{\bullet}\right)$;

$258(2, f=0.01), 188(1), 181(2)\left(\mathrm{HC} \equiv \mathrm{C}^{+} \leftarrow \mathrm{Ar}\right)$; 276 (1), 265 (2), $182(2), 180$ (1) ( $\mathrm{HC} \equiv \mathrm{C}-\mathrm{C} \equiv \mathrm{CH})$; $214(1)\left(\mathrm{HC} \equiv \mathrm{C}^{+}\right)$.

В расчетах ограничивались длинами волн до $180 \mathrm{~nm}$ снизу, в скобках - число линий и сила осцилятора $f$ в тех случаях, когда $f \geq 0.01$. Интенсивные линии на длинах волн от $260 \mathrm{~nm}$ и меньше присутствуют только в спектрах газового разряда, в котором исходными углеводородами для формирования дендрита являлись продукты деструкции РР. Рассчитанные полосы поглощения и положение наиболее интенсивных линий хорошо согласуются с экспериментальными данными, что свидетельствует о выполнении необходимых условий для образования молекул-,,оовушек“ в газовом разряде.
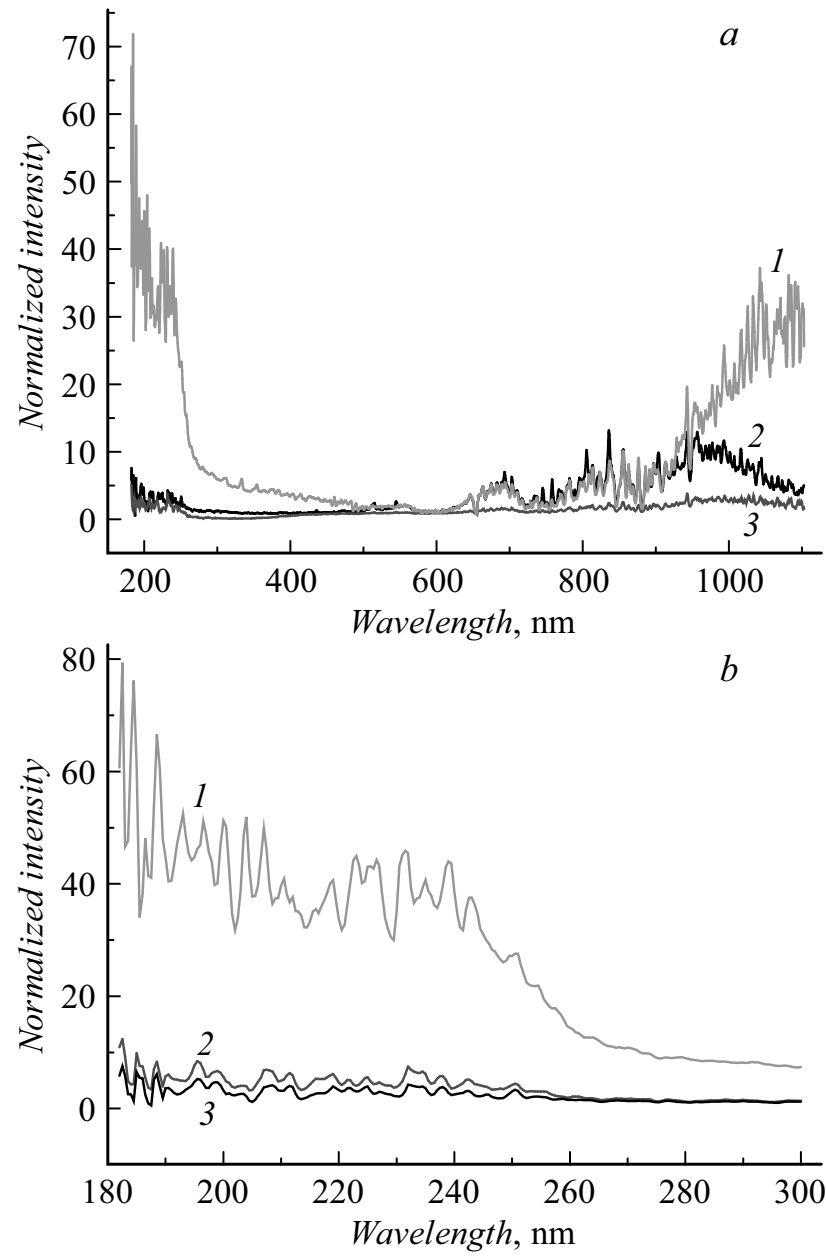

Рис. 2. Нормированные оптические спектры газового разряда, в котором формируется дендрит из исходных углеводородов. $a: 1-\mathrm{PP}, 2-\mathrm{PS}, 3-\mathrm{PE} ; b-$ коротковолновая область спектров более крупно.

Исследование углеродных дендритов на предмет установления наличия в них атомов аргона и места их локализации осуществлялось методом оже-спектроскопии на оже-электронном спектрометре JAMP-9510F (JEOL, Япония). Элементный анализ проводился согласно методике ASTME 827-08. Условия проведения исследования - сверхвысокий вакуум (не хуже $1 \cdot 10^{-9}$ Torr), температура $23^{\circ} \mathrm{C}$. Все образцы крепились на образцедержателе с помощью проводящего углеродного скотча (cat. № G3939, Agar Scientific, UK) для растровой электронной микроскопии (РЭМ). Ток первичного электронного пучка при записи оже-спектров составлял $\sim 10 \cdot 10^{-9} \AA$, ускоряющее напряжение $-10 \mathrm{kV}$. Выбор точек и зон элементного оже-анализа осуществлялся по РЭМ изображению. Примеры типовых оже-спектров дендритов, полученных из продуктов деструкции $\mathrm{PS}, \mathrm{PE}$ и $\mathrm{PP}$, приведены на рис. 3. Спектры сняты в центральной области нескольких углеродных дендритов, полученных при одинаковых условиях (исходные углеводороды, плотность разрядного тока, напряженность поля, давление). 

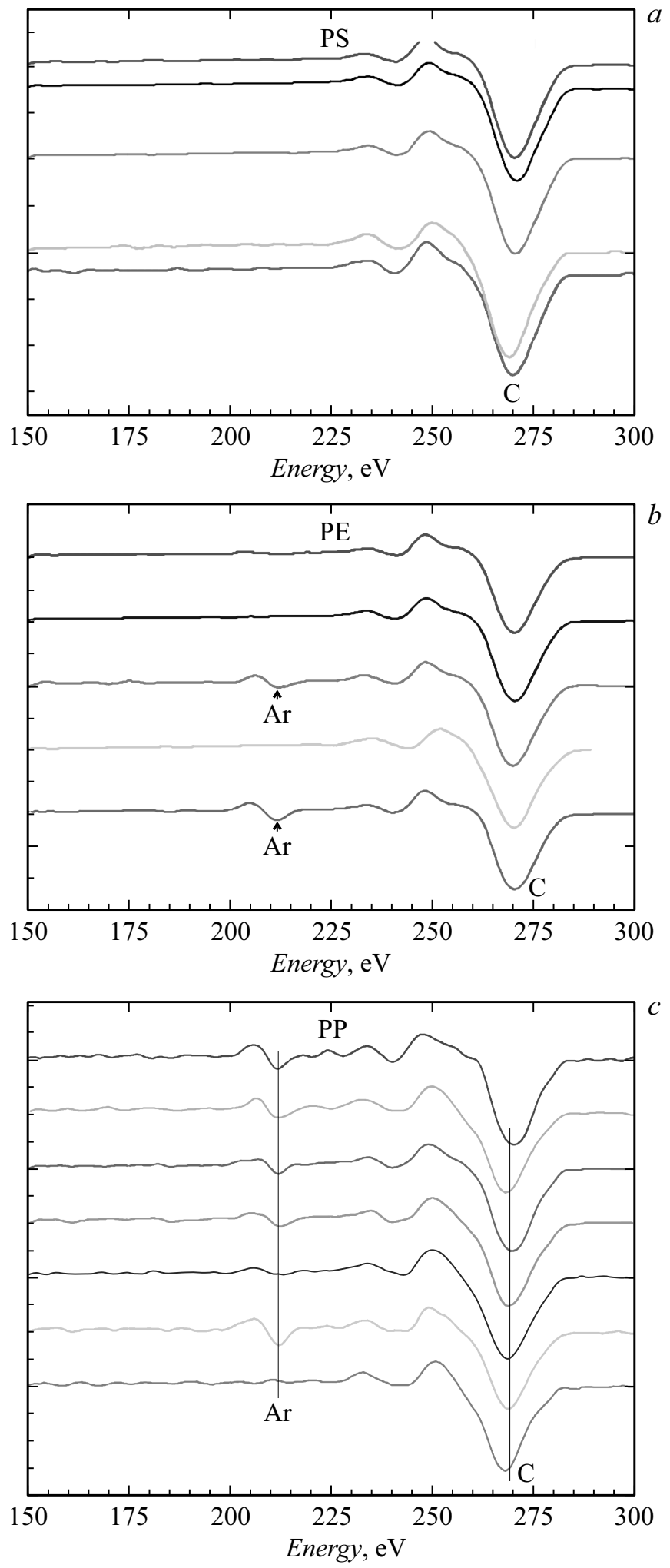

Рис. 3. Типовые спектры дендритов, полученных из продуктов деструкции: $a-\mathrm{PS}, b-\mathrm{PE}, c-\mathrm{PP}$.

Аргон был обнаружен только в центральной части углеродных дендритов, причем в основном в образцах, полученных из продуктов деструкции РР. Полученные результаты соответствуют результатам оптической спек- троскопии газового разряда и косвенно подтверждают, что „пленение“ атомов аргона обусловлено образованием молекул со связью $\mathrm{Ar}-\mathrm{C}$.

Для подтверждения того, что атомы аргона „заперты“ в полостях между хаотично расположенными графеновыми „чешуйкам“, была проведена вторая серия экспериментов.

Если атомы аргона действительно находятся в полостях между хаотично расположенными графеновыми „чешуйками“, то при упорядочивании такой углеродной структуры они начнут выходить из полостей, в которых располагаются. Типовое расстояние между слоями графена больше диаметра атома аргона [15]. Упорядочивание углеродной структуры происходит при повышении температуры. Следует отметить, что при нагревании хаотично расположенных графеновых „чешуек“ в диапазоне $\sim 1200-2000^{\circ} \mathrm{C}$ начинает происходить их упорядочивание в пространстве без изменения строения самих графеновых „чешуек“ $[8,15]$, поэтому во второй серии экспериментов углеродные дендриты, содержащие в ядре атомы аргона, нагревались до температур $\sim(1500 \pm 100)^{\circ} \mathrm{C}$ при давлении $\sim(1 \pm 0.5) \cdot 10^{-5}$ Torr, после чего проводились повторные исследования этих дендритов методом ожеспектроскопии. Типовые оже-спектры „отожженных“ дендритов представлены на рис. 4.

В „отожженных“ дендритах, ранее содержащих атомы аргона, последних не обнаружено. Это подтверждает, что атомы аргона располагаются в полостях, образованных хаотично упорядоченными графеновыми „чешуйками“.

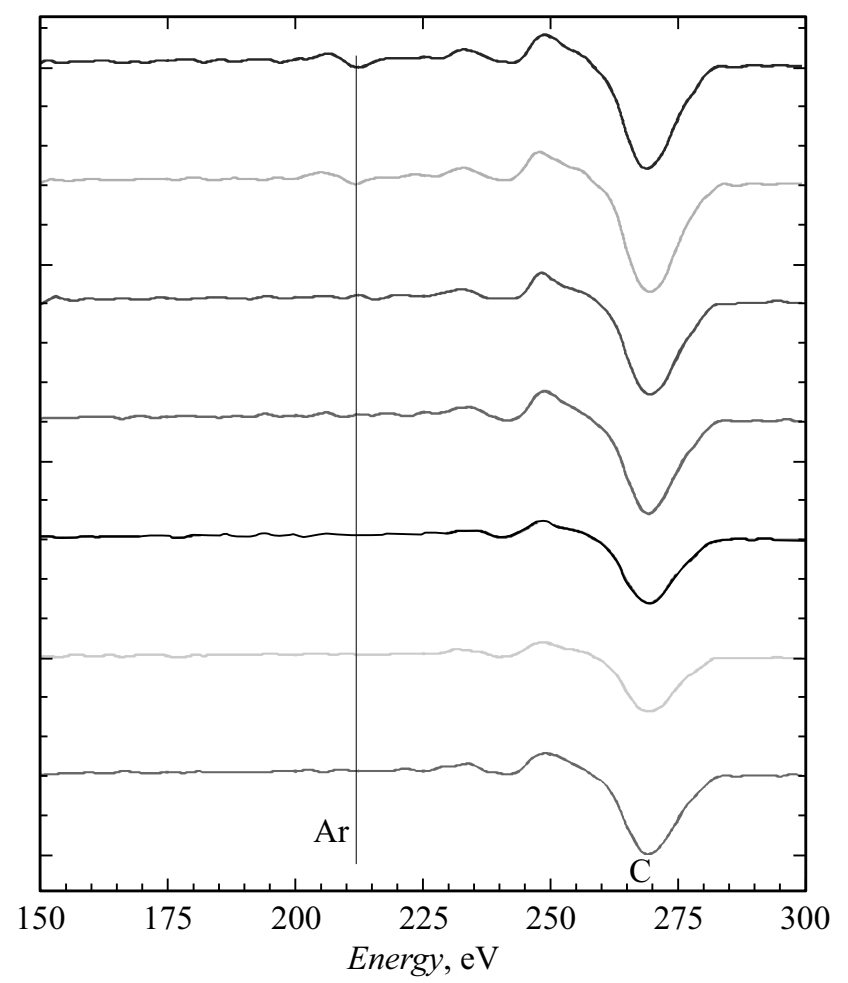

Рис. 4. Типовые оже-спектры „отожженных“ дендритов. 
Проведенные квантово-химические расчеты и эксперименты подтверждают, что образование клатратов аргона с углеродными дендритами, полученными в разряде, происходит за счет разницы в характерных временах времени „жизни“ молекул, содержащих атомы аргона, и времени образования связей $\mathrm{C}-\mathrm{C}$. За время „жизни“ молекул со связью $\mathrm{Ar}-\mathrm{C}$ вокруг них успевают образоваться хаотично расположенные графеновые „чешуйки“, и атом аргона оказывается ,запертым“ в полости между этими „чешуйками“. Следует отметить, что образование клатратов аргона с углеродными дендритами возможно только при одновременном выполнении нескольких условий: условия образования молекул-, ловушек“ в разряде; относительно низкой температуре в центральной части дугового разряда, а также наличии активных частиц углерода, образуемых за счет разложения в плазме исходных углеводородов. Выполнение всех этих условий определяется в основном составом смеси исходных углеводородов и плотностью тока разряда, что подтверждено экспериментальными исследованиями.

\section{Список литературы}

[1] 1 Shevelkov A.V., Kovnir K.A., Zaikina J.V. // Springer Ser. Mater. Sc. 2014. Vol. 199. P. 125-167.

[2] Jia J., Liang Y., Tsuji T., Murata S., Matsuoka T. // Sci. Rep. 2017. Vol. 7. N 1. P. 1290.

[3] Данилаев М.П., Богослов Е.А., Польский Ю.Е., Насыбуллин А.Р., Пудовкин М.С., Хадиев А.Р. // ЖТФ. 2017. Т. 87. Вып. 2. C. 68-73.

[4] Kim D.Y., Kume T. // Jpn. J. Appl. Phys. 2017. Vol. 56. N 5. P. 05 FA07.

[5] Thakor A.S., Gambhir S.S. // Cancer. 2013. Vol. 63. P. 395418.

[6] Lammers T., Rizzo L.Y., Storm G., Kiessling F. // Clin. Cancer Res. 2012. Vol. 18. P. 4889-4894.

[7] Kozak D., Shibata E., Iizuka A., Nakamura T. // Carbon. 2014. Vol. 70. P. 87-94.

[8] Wang G., Yang J., Park J., Gou X., Wang B., Liu H.,Yao J. // J. Phys. Chem. C. 2008. Vol. 112. P. 8192-8195.

[9] Akinwande D., Brennan C.J., Bunch J.S., Egberts P., Felts J.R., Gao H., Huang R., Kim J.S., Li T., Li Y., Liechti K.M., Lu N., Park H.S., Reed E.J., Wang P., Yakobson B.I., Zhang T., Zhang Y.W., Zhou Y., Zhu Y. // Extrem. Mech. Lett. 2017. Vol. 13. P. 42-77.

[10] Данилаев М.П., Богослов Е.А., Польский Ю.Е. // Письма в ЖТФ. 2014. Т. 40. Вып. 19. С. 60-66.

[11] Смирнов Б.М. // УФН. 1983. Т. 139. Вып. 1. С. 53-81.

[12] Neese F. // Wiley Interdiscip. Rev.: Comput. Mol. Sci. 2012. Vol. 2. P.73-78.

[13] Данилаев М.П., Богослов Е.А., Морозов О.Г., Насыбуллин А.Р., Пашин Д.М., Польский Ю.Е. // Инженернофизический журнал. 2015. № 2. С. 748-753.

[14] Cohen A., Lundell J., Gerber R.B. // J. Chem. Phys. 2003. Vol. 119. P. 6415-6417.

[15] Deshmukh A.A., Mhlanga S.D., Coville N.J. // Mater. Sci. Eng. R. 2010. Vol. 70. P. 1-28. 